\title{
COMBATING CONFLICT IN THE WORKPLACE: THE CONTENT AND EFFECT OF A CONFLICT MANAGEMENT AND ASSERTIVENESS TRAINING PROGRAMME
}

\section{Marili Williams, Mike Weyers}

\section{INTRODUCTION}

Conflict and bullying in the workplace remain issues that employers tend to sweep under the proverbial carpet, partly because of the stigma involved and partly because of their own doubt about how the problem should be addressed (Anon., 2001:1-2; Beswick, Gore \& Palferman, 2006:1, 21-25; Dijkstra, Van Dierendonck \& Evers, 2005:119-121; Simpson, 2001:1-6). The tendency has been either to ignore the problem or, at most, minimise its consequences. These consequences more often than not take the form of high levels of stress amongst employees or high absenteeism and staff turnover rates, or both. The current dominant approach is in many respects akin to blaming the victim and closing the door after the horse has bolted (Dijkstra et al., 2005:119-121; Kennedy, 2004:1-3).

In September 1999 the Police Social Work Service (PSWS) of the South African Police Service (SAPS) embarked on a process of developing and delivering proactive services aimed at addressing the social problems that were evident in the organisation (Williams \& Weyers, 2006:39). These problems, identified and analysed by the independent research consultancy Ask Africa (Stutterheim \& Weyers, 2004:2), included personnel conflict and stress (Ask Africa, 1997:28). The service originally took the form of a structured personnel capacitybuilding programme that targeted existing employees. In 2004 this service was, at the behest of the then National Commissioner, expanded to include all recruits who entered the organisation. It took the form of the target group specific Self-Management Programme that formed part of their basic training.

Although the effect of both programmes has been subjected to in-depth analysis, this article will only cover the nature and results of the training of SAPS recruits. It is, however, first necessary to put the true cost of conflict in the workplace into perspective.

\section{CALCULATING THE TRUE COST OF CONFLICT IN THE WORKPLACE}

In 2001 the International Labour Organization (ILO) commissioned a comprehensive study of the cost of violence/stress in the workplace. The researchers came to the conclusion that "approximately $30 \%$ of the workforce in developed countries, and possibly even a higher proportion in newly industrialised and developing countries, suffer from work-related stress" and that "in total stress and violence at work may account for 1-3.5\% of GDP" (Hoel, Sparks \& Cooper, 2004:3,5). For South Africa this price tag would have come to between R60.61 billion and R177.14 billion in 2008 (CIA, 2009).

Conflict can generally be defined as a state of disharmony that exists between incompatible or diametrically opposed parties (University of Wisconsin, 2008:1). In this definition the concept "disharmony" constitutes something more than a mere disagreement - it is a situation in which people perceive an incident or state as a threat to their wellbeing (Dijkstra et al., 2005:120123; University of Wisconsin, 2008:1-2). "Normal", low-key conflict is a natural occurrence in human relationships and often a prerequisite for effective collaboration. It becomes problematic, however, when the threat is realised and a person's physical and or psychosocial wellbeing is compromised (De Dreu, Van Dierendonck \& Dijkstra, 2004:6-12). This leads to 
excessive and sometimes debilitating stress, also known as "conflict stress" (Giebels \& Janssen, 2005:137-139).

It is difficult to differentiate between stress as a cause and as a consequence or symptom of conflict (De Dreu et al., 2004:9-20). There is strong evidence that highly stressed persons are more likely to come into conflict with others than those experiencing "normal" levels (Giebels \& Janssen, 2005:137-141). The "conflict event", however, need not necessarily be triggered by stress. More often than not other factors play a role. The high levels of aggression in society, for example, could spill over into the workplace and on occasion lead to worker-on-worker violence. Recent international research has also indicated that the emotional and psychological abuse referred to as "bullying" and "mobbing", rather than the physical violence, represents a greater threat to more workers (Hoel et al., 2004:6). This is closely followed by harassment on the basis of gender and race and by verbal abuse (Beswick et al., 2006: 8-9, 13-15; Chappell \& Di Martino, 2000). All these types of conflict situations are also prevalent in South Africa (Heintz, 2000:9,12; Kennedy, 2004:1-3).

The cost of conflict and its associated stress can be enormous. Apart from the emotional distress and exhaustion that victims suffer, international research has indicated that it leads to high staff turnover rates and various types of absenteeism (Giebels \& Janssen, 2005:137-41). If these international trends are applied to South Africa, it would mean that local employers lose billions of rand annually because of employee conflict.

In determining the costs of conflict-related staff turnover, it should first be noted that internationally between $15 \%$ and $25 \%$ of personnel who leave organisations do so because of bullying (Hoel et al., 2004) and that $40 \%$ of all staff turnover (death and retirement excluded) could be related to stress (Lee, 1997:33-38). The cost of replacing a skilled employee is conservatively estimated at: $150 \%$ of that individual's annual compensation (DMI, 2001). This formula is based on the view that the total cost of staff turnover is equal to:

- total separation costs (administrative and production loss);

- plus total replacement costs (hiring cost and expenses);

- plus total training costs (orientation, formal training and trainers);

- plus net differential of performance between leaver and replacement (former worker production minus new worker production) (DMI, 2001).

Absenteeism and its concomitant loss of work hours can take on a variety of forms. The first is an increase in sick leave. If the findings of various studies are used as a basis, the cost of bullying and stress-induced sick leave can be calculated as: $15 \%$ of workforce $x 7$ days per annum $x$ average worker cost per hour. This formula is based on findings that:

- at least $15 \%$ of the personnel of an organisation will be the victims of bullying;

- these personnel will take seven more sick leave days than those not affected or, if calculated differently;

- their work incapacity will last 2.5 times longer and cost 5 times that of other staff members (Barnes-Slater \& Ford, 2004; BSHWS, 2000; Gabriel \& Liimatainen, 2000; Hoel et al., 2004).

Illness-related absenteeism may also take on other forms than "formal" sick leave. One of the cost items that is often overlooked is the time spent by employees away from work because of visits to a medical practitioner. Alper (2002) estimated that it would be at least four hours per worker per medical certificate. 
Conflict also impacts on the productivity of an organisation in other ways. Barnes-Slater and Ford (2004), for example, estimate that $50 \%$ of all grievances are caused by conflict and stress. One such grievance will cost an organisation in excess of 80 hours in lost productivity by the worker and his/her co-workers (Lee, 1997). It has also been found that $30 \%$ of a typical manager's time is spent on dealing with conflict and conflict-related issues (e.g. conflict, absenteeism and staff turnover) (Barnes-Slater \& Ford, 2004).

Bullying and conflict also have a negative impact on general workflow. According to Hoel et al. (2004), it is equal to $10 \%$ of the combined cost of the staff members who are involved in a particular conflict situation. There are usually at least three such persons, viz. the aggressor, the victim and one manager.

There are numerous other conflict-, bullying- and stress-related costs to an organisation. These include (Gabriel \& Liimatainen, 2000; Hoel et al., 2004; Lee, 1997):

- health care costs (e.g. the increases in health care-related expenses to the employer as a result of stress-related [psychogenic] illnesses are equal to $2 \%$ of combined cost of the personnel in conflict);

- the cost of disciplinary hearings (e.g. the lost productivity because of disciplinary hearings is estimated at a combined 160 work hours per hearing for all the role-players involved);

- damages (e.g. the cost of conflict-incited damage to the employer's property, fraud, theft and embezzlement is equal to $2 \%$ of personnel's expected contribution to organisational profitability);

- presenteeism cost (lost productivity because of employees using work time to discuss conflict or bullying-related incidents or issues with fellow workers).

The above overview ought to place the true cost of conflict, bullying and their associated stress in perspective. If the prevalence rates of such occurrences could be lowered, it would not only benefit the psychosocial wellbeing of personnel, but also the "bottom-line" of the organisation. One mechanism that could be used to achieve this goal is equipping staff members with appropriate conflict management and assertiveness skills.

\section{THE CONFLICT MANAGEMENT AND ASSERTIVENESS TRAINING OF SAPS RECRUITS}

In the SAPS conflict management and assertiveness training of recruits constitute two of the nine modules that make up the Self-Management Programme (Diagram 1). They also represent the two focal points of the Human Relations component of the programme (Brooks, 1984:6). The overall purpose of this programme is to empower recruits with the knowledge, attitudes and skills that they would require to behave in a professional and responsible manner, to adhere to and practise sound human relations, to render a professional customer service and to become resilient police officials (SAPS, 2004; Stutterheim \& Weyers, 2004:10).

The modules form part of the basic training of all SAPS recruits and have a combined duration of four hours. One social worker (presenter/facilitator) is assigned to each platoon of between 28 to 36 recruits and is responsible for presenting the complete programme, including the two modules to them. The sessions take the form of a workshop in which extensive use is made of social group work techniques and experiential learning methods. During sessions platoons are sometimes divided into four or five smaller groups in order to ensure optimal participation in discussions and experiential learning activities. 


\section{DIAGRAM 1}

\section{THE COMPOSITION OF THE SAPS SELF-MANAGEMENT PROGRAMME}

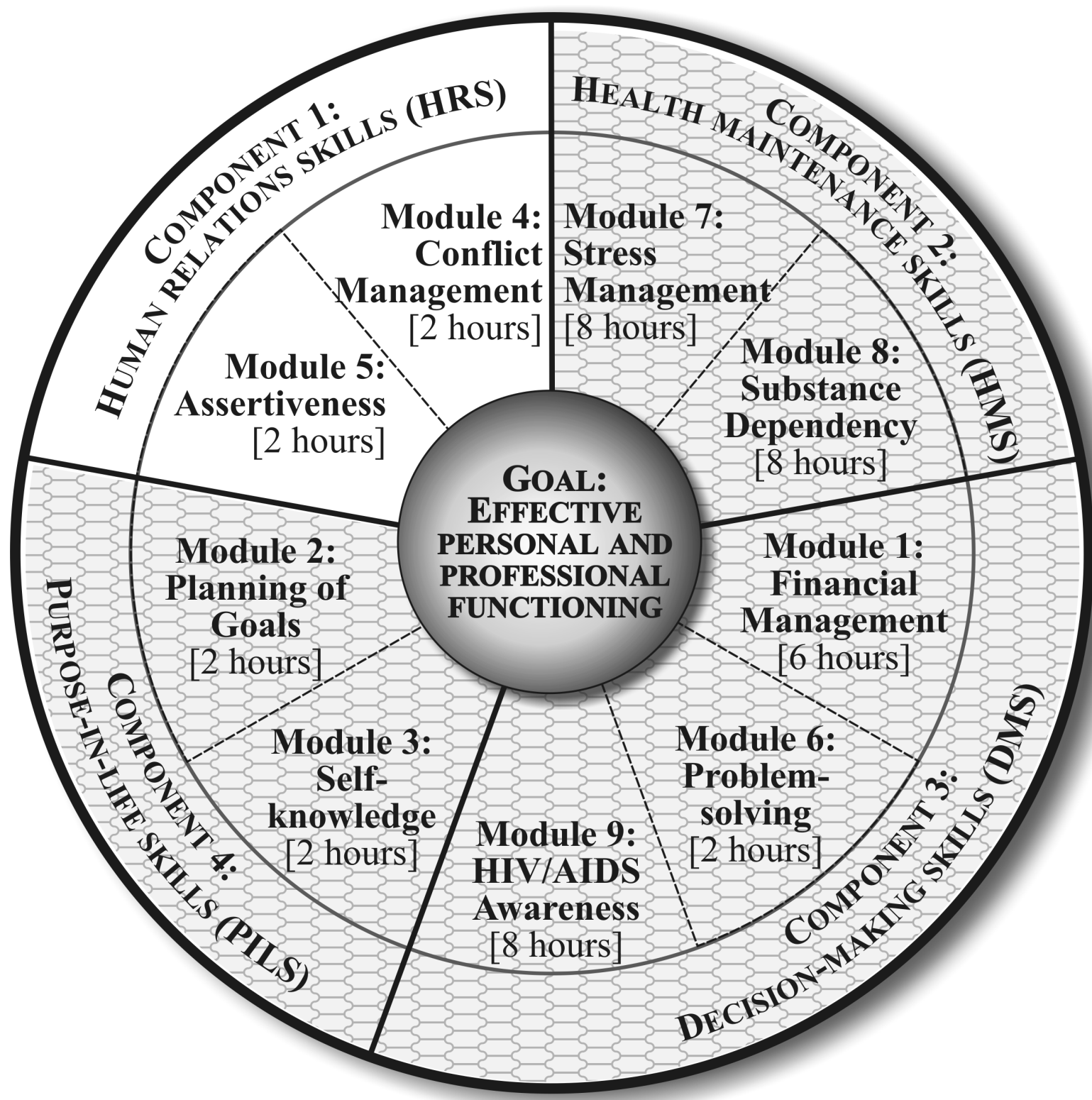

In the programme conflict management and assertiveness are viewed as two complementary skills categories. The effective management of conflict is only possible if the person involved possesses sufficient assertiveness skills and the latter is one of the skills sets that are required to prevent conflict in the first place (Brooks, 1984:5-11).

The contents and main teaching activities of both modules are summarised in Table 1 and will be discussed in more detail. These data could be used as a basis for the development of similar training initiatives in other settings. 
TABLE 1

THE THEMES AND PRESENTATION METHODS OF THE CONFLICT MANAGEMENT AND ASSERTIVENESS MODULES*

\begin{tabular}{|c|c|}
\hline SUBJECT \& THEMES & METHODS \\
\hline \multicolumn{2}{|c|}{ Module 4: Conflict management [Duration: 2 hours] } \\
\hline - Introduction of the topic & Presentation to large group \\
\hline - Defining "conflict" & Small group discussion and feedback \\
\hline - The reasons for conflict & Discussion and role-play \\
\hline - Feelings that are evoked by conflict & Debate \\
\hline - Behaviour that intensify conflict & Group discussion \\
\hline - Five primary strategies for managing conflict & Questionnaire and discussion \\
\hline - Guidelines for effective conflict management & Small and large group discussions \\
\hline - Summary and closing & Large group \\
\hline \multicolumn{2}{|c|}{ Module 5: Assertiveness [Duration: 2 hours] } \\
\hline - Introduction of the topic & Presentation to large group \\
\hline - Definition of self-assertive behaviour & Small group discussion and feedback \\
\hline - Passive, aggressive and assertive behaviour & Presentation, role-plays and discussion \\
\hline - Personal rights & Small group discussion \\
\hline - Assertive philosophy & Group discussion \\
\hline - Summary and closing & Large group \\
\hline
\end{tabular}

*(SAPS, 2004) (Note: The programme/modules are copyrighted)

\section{The conflict management module}

The goal of the module is to sensitise recruits to the fact that there are different styles of conflict management, to help them identify which style they typically use (and to make them aware of its advantages and disadvantages), and to help them select and utilise the styles that would be most appropriate to the different situations that they might be confronted with in practice (SAPS, 2004). One of the core points of departure is that conflict creates an opportunity for the individual to grow and to learn more about him/herself and others (Cloke \& Goldsmith, 2000:32).

The module covers six primary themes that are explored through presentations, discussions, exercises and role-plays. They are:

- defining of the concept "conflict";

- the reasons for or causes of conflict; 
- the feelings that are evoked by conflict;

- behaviours that intensify conflict;

- the five primary strategies for managing conflict; and

- guidelines for the application of the most appropriate strategy or strategies in practice.

Only the core elements of each of the themes and the process that is followed in their presentation will be covered next. This ought to give some indication of how the module is implemented in practice and the role(s) that the social worker (presenter/facilitator) plays in this regard.

\section{Theme 1: Defining "conflict"}

After introducing the theme and purpose of the module, as well the "rules of engagement" (i.e. reciprocal expectations of presenters and participants), the next step is to establish a uniform baseline for learning. This is done by first giving the recruits the opportunity to develop their own definition of conflict. This is done in small groups. Each group is then given the chance to share their definition with the rest of the platoon. This is followed by an exploration and discussion of the implications of each definition within the larger group.

Throughout the exploration and discussion process it is emphasised that, although there are many different definitions of conflict, any new attempt should contain at least one of the ideas expressed by either Bush and Folger (1994) or Folger, Poole and Stutman (2000). These are that "conflict exists because of a real or apparent incompatibility of parties' needs or interests" (Bush \& Folger, 1994:3) or that conflict is "the interaction of interdependent people who perceive incompatible goals and interference from each other in achieving those goals" (Folger et al., 2000:5). It is also stressed that conflict is a "product" of interpersonal interaction, that it is sustained by the behaviours of the parties involved and that their actions and reactions to one another occur on both the verbal and non-verbal communication levels (Folger et al., 2000:5).

\section{Theme 2: The reasons for conflict}

Once the recruits agree on a definition, the causes of conflict are explored through a group discussion. During this discussion they are made aware of how differences in values, procedures, interests, available data and communication styles, as well as the nature of a relationship, could contribute to conflict (Isenhart \& Spangle, 2000:14-16).

The process then moves on to a number of role-plays in which the recruits participate. The scenarios that are provided are formulated in such a way that they contain examples of typical differences. Through the role-plays the recruits also experience first hand how conflict can influence relationships and affect the individual on an emotional level.

\section{Theme 3: Feelings that are evoked by conflict}

The role-plays usually bring a variety of emotions to the surface. The facilitator then encourages the recruits to identify these feelings and their impact on the conflict situation. They are then made aware of Isenhart and Spangle's (2000:17) statement that "people will reciprocate in an intensified and negative manner to behaviours they perceive as threatening, devaluing or insulting. The more threatening the communication, the more ... emotions such as blame, fear and anger intensify."

The recruits are also sensitised to the fact that as the conflict spiral progresses, the parties in disagreement could become so caught up in their emotions that the original root cause of the conflict is no longer the issue at hand. This, coupled with different perceptions of the same 
event or set of circumstances, makes some disputes extremely difficult to resolve. The role that differences in perceptions could play is then illustrated with the help of visual brainteasers such as pictures depicting more than one face, dimension or art effect.

\section{Theme 4: Behaviours that intensify conflict}

Cloke and Goldsmith (2000:3-4) identified aggressive, judgmental, hypercritical, passive, apathetic or defensive behaviours as contributing factors to the intensification and the nonresolution of conflict. Recruits are consequently engaged in an exploration of these typical but non-effective responses. The discussion is handled in such a way that they would come to the conclusion that these types of behaviour would impact negatively on the conflict-resolution process and that they could not improve a relationship, only worsen it.

The discussion of the behavioural patterns that would intensify interpersonal and group conflict concludes the part of the module that deals with the nature of the conflict phenomenon. The focus then shifts to more appropriate and effective ways to deal with it.

\section{Theme 5: Five primary strategies for managing conflict}

The stated point of departure in theme 5 is that, although people tend to develop a preferred conflict handling or resolution style based on their past family, work and life experiences (Isenhart \& Spangle, 2000:26-7), most also have the innate ability or flexibility to respond differently to different types of conflict situations (Barsky, 2000:41). The style that they use at home may, for example, differ from that which they use at work. The choice of style is mostly influenced by the importance of the issue involved and the contextual or cultural prescriptions on how such conflict should be dealt with.

After introducing the theme, each recruit is requested to complete a conflict management questionnaire. Its results, which are kept confidential, indicate the extent to which he or she would "normally" use one or more of the competing, avoiding, compromising, accommodating and collaborating styles (Barsky, 2000:42-43; Folger et al., 2000:69; Isenhart \& Spangle, 2000:26-27).

The general nature, as well as the pros and cons, of each of the styles is then discussed by the group. The presenter/facilitator would during this process emphasise the fact that the collaborative style is most useful when conflict within an organisational setting needs to be resolved. Participants are also made aware of Isenhart and Spangle's (2000:27) description of this style as "characterised by active listening and issue-focused empathic communication that seeks to satisfy the interests and concerns of all parties".

\section{Theme 6: Guidelines for effective conflict management}

The final theme, namely the guidelines for effective conflict management, is covered in some depth through small and large group discussions. Some of the guidelines that are emphasised are that recruits should, in conflict situations, take responsibility for their own thoughts and feelings, should be specific, should use "I" messages, should maintain good eye contact and should respect the other party's views.

The module presentation is concluded with a summary of the main conclusions that could be drawn from it. It is usually emphasised that every relationship contains elements of conflict, disagreement and opposing interests. Conflict tends to generate various (negative) emotions, including anger. The failure to handle conflict in a constructive way could lead to the destruction of a relationship. However, if it is managed with the appropriate style and in a skilful manner, it could enrich the relationship. The participants are then urged to reconsider, 
where necessary, their preferred conflict management style as identified through the questionnaire and to adopt a style that is more appropriate to the situations that they may be confronted with.

The Self-Management Programme is structured in such a way that the assertiveness module follows directly on from conflict management. This allows the presenter/facilitator to explain the direct link that exists between these two forms of human relations skills to the recruits.

\section{The assertiveness module}

The basic aim of the module is to enhance the participants' ability to be assertive in their work and personal lives. In the process four main themes are covered. They are: defining the concept "assertiveness"; the nature of and relationship between passiveness, aggressiveness and assertiveness; personal rights; and the development of a personal "assertive philosophy" (SAPS, 2004).

\section{Theme 1: Defining "assertiveness"}

After introducing the theme and purpose of the module, a quick survey is done on the participants' knowledge of the concept "assertiveness". If their knowledge is inadequate, the facilitator would describe its basic nature and implications as practically as possible to them. They would emphasise the view of assertiveness as the ability of people to express themselves and their rights without violating the rights of others (UIUC, 2005). Assertive individuals are therefore able to ask for what they want or need, but at the same time recognise and heed the needs of others.

Recruits are then given the opportunity to develop their own definition of assertiveness within small groups and to present the results to the platoon for further discussion. If and where necessary, the presenter will stress the fact that assertiveness should not be confused with aggressive behaviour, nor that it need take on an appeasing (non-assertive) character (Civil, 2003:x). This thought paves the way for addressing the next theme of the module.

\section{Theme 2: Passive, aggressive and assertive behaviour}

The theme is introduced with a short presentation on different behaviour styles. In it the emphasis is placed on the nature of, and relationship between, passive, aggressive or assertive behaviour.

Passive behaviour is basically explained to the recruits as follows:

- When one allows the needs, opinions and judgements of others to become more important than one's own, one is likely to feel hurt, anxious and even angry;

- This type of passive or non-assertive behaviour is often indirect, emotionally dishonest and self-denying (Sorensen, 2005).

Aggressive behaviour implies that a person behaves selfishly and in this way violates the rights of others. They therefore lay claim to their own rights, but at the expense of others and/or leading to the humiliation of others. The following typical negative outcomes of aggressive behaviour are then highlighted:

- Aggression often breeds aggression. Once people start behaving aggressively towards each other, it becomes very difficult to stop. This leads to a negative pattern of communication within the relationship;

- Aggression can make a person unpopular. Once such a person has a reputation for being aggressive, people will start to avoid him or her; 
- Aggression discourages people from helping such a person in future, even when they really need help;

- Some people erroneously believe that aggressive behaviour would make others respect them. The fact of the matter is that it would at most only create fear and resentment that would lead to further negative behaviour towards the "perpetrator" (Sorensen, 2005).

When explaining the nature of assertive behaviour, the presenter would emphasise the fact that it consists of three interdependent components. They are behaviour, feelings and consequences. The content of each is illustrated with the help of the following "formula" for assertive interpersonal communication:

"When you (state the behaviour), I feel (state the feeling) because (state the consequence)" (Bramson, 2001; Sorensen, 2005).

After the presentation, volunteers are recruited to take part in different role-plays. These groups are provided with scenarios that are structured in such a way that they would illustrate the different behaviour styles and at the same time show each one's impact on the individuals involved. After each role-play, the group must identify the passive, aggressive and or assertive behaviour styles that came to the fore. The role-players are also afforded the opportunity to practise their responses until all agree that they represent appropriate assertive behaviour.

The role-plays are followed by a discussion of the feelings that the different behaviour styles evoke. During the discussions the presenter would emphasise the importance of the use of "I" messages as a tool in assertive behaviour and the principle that all people have personal rights which should not be violated by others. The latter provides a link to the next theme.

\section{Theme 3: Personal rights}

The next theme of the module is introduced by the presenter who explains that, if people want to express their thoughts, feelings and needs assertively, they must in the first place believe that they have the legitimate right to do so. The following personal rights are then discussed in some detail in small groups:

- The right to decide how to lead one's life;

- The right to one's own values, beliefs, opinions and emotions;

- The right not to justify or explain one's actions to others;

- The right to express oneself and to say "no";

- The right to ask for information or help;

- The right to change one's mind and to make mistakes;

- The right to like oneself, even though one is not perfect;

- The right to have positive, satisfying relationships within which one feels comfortable and free to express oneself honestly;

- The right to change or enhance one's life (Sorensen, 2005:3).

During the feedback session, the presenter would emphasise the fact that people who do not believe that they have these rights would tend to become submissive and only respond passively to circumstances and events in their lives. The most appropriate countermeasure is to create a "personal assertive philosophy". 


\section{Theme 4: A "personal assertive philosophy"}

The nature of a "personal assertive philosophy" is covered by means of a short introduction followed by a group discussion. The presenter would also use this as an opportunity to summarise some of the main issues covered by the module. He/she would go to some lengths to emphasise the fact that assertiveness should be utilised selectively. The basic message is that:

"It is not just what you say to someone verbally, but also how you communicate nonverbally by the tone of voice, gestures, eye contact, facial expressions and posture that determines your impact on others".

The recruits are then finally encouraged to make the identified assertiveness philosophy part of their daily lives.

\section{THE EFFECT OF THE MODULES ON RECRUITS}

Only the basic nature of, and primary results achieved in, the research into the effect of the modules will be covered, because of length constraints.

The primary study was conducted in 2005 and utilised a multi-method research design that consisted of:

- a classic experiment that

- involved 400 experimental group and 120 control group participants and

- utilised Cohen's formula for the calculation of effect size (i.e. "d-value") (Cohen, 1988:20-7; Steyn, 2000:1-3) to measure the short-term effect of the modules on recruits;

- qualitative focus groups sessions that

- were held six to seven months after the initial training,

- involved 47 recruits and

- were aimed at ascertaining the modules' long-term effect; and

- the utilisation of an extensive computerised measurement framework developed by Meyer, Opperman and Dyrbye (2003) to measure the modules' return on investment (ROI).

In the experiment use was made of questionnaires that contained four primary scales. The reliability of each of these scales was determined by means of the utilisation of the Cronbach alpha coefficient (i.e. " $\alpha ")$ (Gravetter \& Forzano, 2003:455). The results of this process are contained in Table 2. 
TABLE 2

CRONBACH ALPHA OF THE CONFLICT MANAGEMENT AND ASSERTIVENESS SCALES ${ }^{*}$

\begin{tabular}{|c|c|c|c|}
\hline \multirow[b]{2}{*}{ SCALE } & \multirow[b]{2}{*}{ FACET \& QUESTION } & \multicolumn{2}{|c|}{$\alpha$} \\
\hline & & $\begin{array}{c}\text { Conflict } \\
\text { management }\end{array}$ & Assertiveness \\
\hline Scale 1 & Objective knowledge & $0.50^{\square}$ & $0.55^{\text {ฮ }}$ \\
\hline Scale 2 & Subjective knowledge & $0.91^{\text {ฮ }}$ & $0.89^{\text {ฮ }}$ \\
\hline Scale 3 & Attitude & Individual items & $0.72^{\text {ฮ }}$ \\
\hline Scale 4 & Behaviour & $0.91^{\varpi}$ & $0.50^{\varpi}$ \\
\hline
\end{tabular}

Reliable scale: $\alpha \geq 0.5^{*}$ (Williams \& Weyers, 2006:54)

All but one of the scales had an acceptable Cronbach alpha coefficient of 0.5 or more. The exception was the "attitude scale" (Scale 3) of conflict management. This deficiency was probably a result of some of the questions that were utilised. Because of this, only individual questions from the scale could be used as indicators of the particular effect.

Only the main finding regarding the effect of the modules will be provided.

\section{The effect of the conflict management module}

The short-term effect of the module on recruits is summarised in Table 3. A d-value of 0.8 and above would indicate a large effect that is of practical significance. A value between 0.5 and 0.79 would indicate a medium effect and imply that, although the result can be viewed as significant, an improved research instrument or procedure could have produced even more significant results (Cohen, 1969:22-25; Spatz, 2001:74-75; Steyn, 1999:3).

TABLE 3

THE COVARIANCE ANALYSIS FOR SCALES 1 - 4: CONFLICT MANAGEMENT*

\begin{tabular}{|c|c|c|c|c|c|}
\hline SCALE & $\mathbf{n}$ & DIFFERENCE & MSE & $\begin{array}{c}\text { p- } \\
\text { VALUE }\end{array}$ & $\begin{array}{c}\text { d- } \\
\text { VALUE }\end{array}$ \\
\hline $\begin{array}{l}\text { Scale 1: Objective knowledge of conflict } \\
\text { management }\end{array}$ & 513 & 0.056 & 0.472 & $<.0001$ & $1.07^{* *}$ \\
\hline $\begin{array}{l}\text { Scale 2: } \begin{array}{l}\text { Subjective knowledge re conflict } \\
\text { management }\end{array}\end{array}$ & 512 & 1.068 & 0.436 & $<.0001$ & $2.40 * *$ \\
\hline Scale 3: Attitude re conflict management & - & - & - & - & - \\
\hline $\begin{array}{c}\text { Scale 4: Behaviour re conflict } \\
\text { management }\end{array}$ & 510 & 0.774 & 0.429 & $<.0001$ & $1.18 * *$ \\
\hline
\end{tabular}

*Medium effect: $d \geq 0.5 * *$ Practical significant effect $: d \geq 0.8^{*}$ (Williams \& Weyers, 2006:56) 
The results of the covariance analysis (Table 3 ) indicate that the conflict management module had a large effect $(\mathrm{d}=1.07)$ on the objective knowledge (Scale 1) and an even larger effect $(\mathrm{d}=2.4)$ on the so-called "subjective knowledge" (Scale 2) of the recruits. In this context Scale 1 measured changes (i.e. an increase or decrease) in the respondents' factual knowledge, whereas the second scale dealt with the extent to which they felt that their knowledge had increased (or not). The core conclusions were that recruits did not originally have much knowledge of the (basic) nature of conflict and conflict management, and that this "ignorance" was eliminated on both the factual and emotional level.

Because the attitude scale (Scale 3) proved to be unreliable $(\alpha=0.422)$, only some of the individual items could be used as indicators. These showed that the module made recruits more willing to address conflict situations and that a collaborative conflict management style was more expectable after the training than beforehand (Williams \& Weyers, 2006:59).

Scale 4 measured the difference between conflict management before and intended behaviour after the presentation of the module. It produced a practical significant effect size of $d=1.1 .8$ (Table 3) which, in terms of the purpose of the module, is very important.

The question then arose as to what extent the intended behaviour would translate into actual and effective conflict management. This was ascertained with the help of the focus group sessions that were held six to seven months after the initial training. From these discussions the following overall trends emerged.

\section{Long-term effect}

The impact of the module on the attitudes and behaviour of recruits was still evident after seven months. They could still recall the different conflict management styles and the different metaphors (linking styles to certain animal behaviours in conflict situations) that were used to illustrate them, as well as the role-plays that were undertaken. These tools and methods reenforced the positive outcome of constructive conflict resolution and contributed to a change in their behaviour patterns.

\section{Effect on relationships}

The recruits mentioned consistently that this module sharpened their general communication and especially listening skills. Appropriate and confident usage of communication skills is crucial in doing their work effectively as police officials as well as in maintaining personal relationships.

\section{Effect on the individual}

According to the recruits, the module:

- increased their self-confidence;

- improved personal motivation;

- increased job satisfaction;

- expanded knowledge on the self, life and its challenges; and

- ensured a greater understanding of different people and their habits and conduct.

From the responses of the focus group members it was concluded that the conflict management module did have a long-term effect on the recruits' knowledge, attitude and behaviour. There was also strong evidence that most of the recruits integrated the new behaviour patterns into their daily functioning. 


\section{The effect of the assertiveness module}

The results of the measurements produced by the four scales of the assertiveness module are contained in Table 4. The discussion of their implications will be combined with some of the issues that came to the fore in the subsequent focus group sessions.

TABLE 4

THE COVARIANCE ANALYSIS FOR SCALES 1-4: ASSERTIVENESS

\begin{tabular}{|c|c|c|c|c|c|}
\hline SCALE & $\mathbf{n}$ & DIFFERENCE & MSE & p-VALUE & d-VALUE \\
\hline $\begin{array}{c}\text { Scale 1: Objective knowledge re } \\
\text { assertiveness }\end{array}$ & 510 & 0.424 & 0.363 & $<0.0001$ & $1.168^{* *}$ \\
\hline $\begin{array}{c}\text { Scale 2: Subjective knowledge re } \\
\text { assertiveness }\end{array}$ & 512 & 1.101 & 0.465 & $<0.0001$ & $2.367^{* *}$ \\
\hline Scale 3: Attitude re assertiveness & 512 & 0.292 & 0.331 & $<0.0001$ & $0.882^{* *}$ \\
\hline Scale 4: Behaviour re assertiveness & 510 & 0.264 & 0.372 & $<0.0001$ & $0.709^{*}$ \\
\hline
\end{tabular}

*Medium effect: $d \geq 0.5 * *$ Practical significant effect $: d \geq 0.8 *$ (Williams \& Weyers, 2006:58)

The content and implications of the concept "assertiveness" are usually regarded as abstract in nature and therefore difficult to explain by a presenter. The large effect size of $\mathrm{d}=1.168$ achieved with the objective knowledge scale (Scale 1) would indicate that they succeeded in this task and that the recruits were able to learn and comprehend the factual knowledge covered in the module. Because of the design of the module and the fact that it is presented in a workshop and not typical teaching format, the big increase in knowledge is somewhat unexpected. It could indicate that the subject matter was new and/or that they found it very interesting.

The responses from the focus group members indicated that their retention span, especially of the implications of assertiveness, was quite long. They could, for example, explain that as police officials one is expected to take charge of a situation, but in an assertive and not aggressive manner. They also knew when to use assertiveness and how to do so without manipulating others.

The very large effect size achieved with Scale $2(\mathrm{~d}=2.367)$ showed that the recruits did not only comprehend the factual information, but also felt that they had mastered the subject. During the focus group discussions it was clear that the members had come to the conclusion that assertiveness and responsibility go hand in hand and felt that they were able to utilise their new knowledge and skills in practice.

Scale 3 produced a practical significant effect size of $d=0.882$ (Table 4 ). This indicates that the intervention changed the recruits' attitudes in a practical significant way. From the focus group sessions it was evident that this change had become part of their frame of reference and that they strove to be assertive in their daily lives.

The medium to large effect size of $\mathrm{d}=0.709$ that was produced by Scale 4 (behaviour) (Table 4) indicated that, although the recruits had mastered the knowledge dimension and would strive to be more assertive, they did not master all the skills associated with this behaviour pattern during training. This could to some extent be attributed to the training milieu in which they found themselves and the subordinate role that they were required to fulfil during basic 
training. The focus group sessions, however, indicated that they found it easier to put their assertiveness skills into practice once they had finished their training.

The focus group discussions also brought various other issues to the fore. Only some overall trends will be highlighted here.

\section{Impact of being assertive}

The recruits experienced that being assertive had a positive impact on relations. Especially when dealing with difficult people, this tool helped them to be reasonable and professional. They also found that being assertive built their self-confidence. This enabled them to experience work, life and people more positively.

\section{Effect on knowledge, attitude and behaviour}

The respondents remembered and understood the difference between passive, aggressive and assertive behaviour and the consequences of each of these styles. An assertive attitude and behaviour made them feel more professional, helped them to express themselves in an adult manner and prevented them from violating the rights of others.

If the results of the short-term effect measurements are combined with recruits' responses during the focus group sessions, it becomes evident that the assertiveness module succeeded in its primary goal. This is, namely, to equip recruits with the knowledge, attitudes and skills that are necessary to be more assertive individuals. They generally placed a high value on the new "equipment" they felt empowered them as well as the conflict management module.

\section{MAIN FINDINGS}

The student constables of today do not only represent the workforce of the South African Police Service of tomorrow, but also an investment of billions of the taxpayers' rands. It is therefore imperative that they should be empowered to function effectively as police officials and as human beings and that this empowerment process should be conducted in a costeffective manner. The empowerment process should include attempts to enable them to deal effectively with interpersonal conflict and to behave in an assertive manner. For this purpose, two content-specific modules dealing with conflict management and assertiveness were included in their basic training.

The study into the effect of the modules indicated:

- that they had a practical significant short-term effect on the recruits' knowledge, attitudes and (intended) behaviour;

- that this effect lasted for at least six months after the initial training; and

- that the modules did not only function as a work-related empowerment tool, but also enriched the recruits' personal lives.

A further cost-benefit analysis of the modules indicated that they would produce a return on investment (ROI) coefficient of more that $5.000 \%$ per annum and that, because of lower staff turnover and absenteeism rates, the SAPS would recoup its investment in the training within less than a month (Weyers, Williams \& Huisamen, 2006:121-132).

It was concluded from the study that through the empowerment training, police social workers did not only make a difference in the lives of the recruits, but also that their services were a financial asset for the organisations that employs them. 


\section{IMPLICATIONS FOR OCCUPATIONAL AND GENERIC SOCIAL WORK PRACTICE}

Although there is general consensus that South Africa is a violent society (Kennedy, 2004:1-3), the tendency thus far has been to perceive this phenomenon only in terms of crime statistics (CSVR, 2007:6-12). The incidence of conflict, bullying, mobbing, verbal abuse and gender and race-based harassment in the workplace and community, which can sometimes escalate into physical violence, has often been ignored - this in spite of the high cost in human suffering and lost productivity.

There are ways in which social workers in occupational settings and generic practice could contribute to the elimination of these problems. This includes striking at two of the root causes of conflict, viz. a lack of appropriate conflict management and assertiveness skills.

Within an occupational setting it would require that management would have to be persuaded that there is a need for such training. In most instances an analysis of worker-on-worker violence, grievances, disciplinary hearing, sick leave, absenteeism and staff turnover rates should provide enough data to substantiate such a request. If necessary, this could be supplemented with the results of interviews with supervisors/managers on the amount of time they spend on dealing with conflict and conflict-related issues. The practitioner's case could be further strengthened if the required data on lost production time are translated into monetary terms.

If the SAPS experience is taken as a yardstick, significant training results can be achieved within as little as four dedicated training hours. An alternative would be to make conflict management and assertiveness a substantive part of other training endeavours. Whichever route is followed, it should be noted that the required results would not be achieved if "traditional talk and chalk" training procedures are used. The subject matter requires a workshop format and a presenter/facilitator who is conversant in the application of social group work techniques.

The same basic principles as the above also apply to social workers in generic practice. Conflict management and assertiveness training should form part and parcel of their community education brief. There is especially a dire need that at-risk youths and other vulnerable groups should be targeted.

By addressing the root causes of conflict, practitioners in occupational and generic settings could help to decrease the high rate of violence in South African society.

\section{REFERENCES}

ANON. 2001. TUC Survey results. UK National Work-stress Network News, 1(1):1-2.

ALPER, S. 2002. Is stress nibbling away at your bottom line? Link \& Learn eNewsletter, November. Available: http://www.linkageinc.com/company/news_events/link_learn_enewsletter/archive/2002 [Accessed: 3/4/2005].

ASK AFRICA. 1997. South African Police Service: social work services needs assessment: research report. Pretoria: SAPS.

BARNES-SLATER, C. \& FORD, J. 2004. Measuring conflict: both the hidden costs and the benefits of conflict management interventions. Available: http://www.lawmemo.com/articles/ measuring.htm [Accessed: 23/12/2005].

BARSKY, A.E. 2000. Conflict resolution for the helping professions. Belmont (CA): Wadsworth/Thompson Learning. 
BESWICK, J., GORE, J. \& PALFERMAN, D. 2006. Bullying at work: a review of the literature. Harpur Hill: Heath \& Safety Laboratory.

BRAMSON, R. 2001. Assertiveness skills and dealing with difficult people. Available: http://www.whatsdrivingyou.org/resources/readingroom/asertiveness.html [Accessed: 05/09/ 2005].

BRISTOL STRESS AND HEALTH AT WORK STUDY. 2000. The scale of occupational stress. London: HSE Books.

BROOKS, D.K.J. 1984. A life-skills taxonomy: defining elements of effective functioning through the use of the Delphi technique. Ann Arbor: UMI Dissertation Services.

BSHWS see Bristol Stress and Health at Work Study.

BUSH, R.B. \& FOLGER, J.P. 1994. The promise of mediation: responding to conflict through empowerment and recognition. San Francisco: Jossey-Bass Publishers.

CENTRAL INTELLIGENCE AGENCY. 2009. The World Factbook: South Africa. Available: https://www.cia.gov/library/publications/the-world-factbook/geos/sf.html [Accessed: 26/03/2009].

CENTRE FOR THE STUDY OF VIOLENCE AND RECONCILIATION (CSVR). 2007. The violent nature of crime in South Africa: a concept paper for the justice, crime prevention and security cluster. Braamfontein: CSVR.

CHAPPELL, D. \& DI MARTINO, V. 2000. Violence at work ( $2^{\text {nd }}$ ed). Geneva: ILO.

CIA see CENTRAL INTELLIGENCE AGENCY.

CIVIL, J. 2003. Assertiveness. London: Spiro.

CLOKE, K. \& GOLDSMITH, J. 2000. Resolving conflicts at work. San Francisco: JosseyBass Publishers.

COHEN, J. 1969. Statistical power analysis for the behavioral sciences. New York (NY): Academic Press.

COHEN, J. 1988. Statistical power analysis for the behavioral sciences $\left(2^{\text {nd }}\right.$ ed $)$. Hillsdale (NJ): Erlbaum.

CSVR see Centre for the Study of Violence and Reconciliation (CSVR).

DANA MEDIATION INSTITUTE (DMI). 2001. The Dana measure of financial cost of organizational conflict. Available: http://www.mediationworks.com [Accessed: 08/12/2005].

DE DREU, C.K.W., VAN DIERENDONCK, D. \& DIJKSTRA, M.T.M. 2004. Conflict at work and individual well-being. International Journal of Conflict Management, 15(1):6-26.

DIJKSTRA, M.T.M., VAN DIERENDONCK, D. \& EVERS, A. 2005. Responding to conflict at work and individual well-being: the mediating role of flight behaviour and feelings of helplessness. European Journal of Work and Organizational Psychology, 14(2):119-135.

DMI see DANA MEDIATION INSTITUTE (DMI).

FOLGER, J.P., POOLE, M.S. \& STUTMAN, R.K. 2000. Working through conflict: strategies for relationships, groups, and organizations. New York: Longman Inc.

GABRIEL, P. \& LIIMATAINEN, M.-R. 2000. Mental health in the workplace. Geneva: International Labour Office. 
GIEBELS, E. \& JANSSEN, O. 2005. Conflict stress and reduced well-being at work: the buffering effect of third-party help. European Journal of Work and Organizational Psychology, 14(2):137-155.

GRAVETTER, F.J. \& FORZANO, L.B. 2003. Research methods for the behavioral sciences. Belmont: Thomson/Wadsworth.

HEINTZ, J. 2000. Distribution, investment, and employment in South Africa. TIPS Conference, 18-20 September 2000, Johannesburg, South Africa.

HOEL, H., SPARKS, K. \& COOPER, C.L. 2004. The cost of violence/stress at work and the benefits of a violence/stress-free working environment. Report Commissioned by the International Labour Organization (ILO), Geneva. Available: http://www.workstress .net/bobby/cost.htm [Accessed: 23/11/2005].

ISENHART, M.W. \& SPANGLE, M. 2000. Collaborative approaches to resolving conflict. Los Angeles: Sage Publications.

KENNEDY, M.A. 2004. Workplace violence: an exploratory study into nurses' interpretations and responses to violence and abuse. Bellville: Faculty of Community and Health Sciences, University of the Western Cape. (MCur (Nursing) Mini Thesis)

LEE, D. 1997. Employee stress: the true cost. John Liner Review, 11(3):33-38.

MEYER, M., OPPERMAN, C. \& DYRBYE, C. 2003. Measuring ROI in training. Randburg: Knowres Publishing.

SAPS see SOUTH AFRICA (REP), SOUTH AFRICAN POLICE SERVICE.

SORENSEN, S. 2005. Understanding assertiveness. Available: http://www.mental-healthtoday.com [Accessed: 05/09/2006].

SOUTH AFRICA (REP), POLICE SOCIAL WORK SERVICES. 2004. Life skills. Pretoria: SAPS.

SIMPSON, G. 2001. Violence and social change: some effects on the workplace and some possible solutions. Paper presented to the National EAP Committee of the Institute for Personnel Management Conference, The Role of the EAP in Managing Trauma, Johannesburg, August 1991. Available: http://www.csvr.org.za [Accessed: 25/05/2009].

SPATZ, C. 2001. Basic statistics: tales of distributions. Belmont: Wadsworth/Thompson Learning.

STEYN, H.S. 1999. Praktiese beduidenheid: die gebruik van effekgroottes. (Practical significance: the use of effect sizes) (Wetenskaplike Bydraes, Reeks Natuurwetenskappe nr. 117. Potchefstroom: Publikasiebeheerkomitee, $\mathrm{PU}$ vir $\mathrm{CHO}$ ).

STEYN, H.S. 2000. Practical significance of the difference in means. Journal of Industrial Psychology, 26(3):1-3.

STUTTERHEIM, E. \& WEYERS, M.L. 2004. Strengths-focused intervention: the new approach of the social work service of the South African Police Service (SAPS). Social Work/Maatskaplike Werk, 40(1):1-14.

UIUC see UNIVERSITY OF ILLINOIS.

UNIVERSITY OF ILLINOIS. 2005. Self-help brochures: assertiveness. Available: http://www.couns.uiuc.edu/Brochures/ assertiv.htm [Accessed: 18/11/2005]. 
UNIVERSITY OF WISCONSIN. 2008. About conflict. Available: http://www.ohrd. wisc.edu/onlinetraining/resolution/aboutwhatisit.htm\#whatisconflict [Accessed: 12/02/2009].

WEYERS, M.L., WILLIAMS, H.M. \& HUISAMEN, P. 2006. The return on investment (ROI) of the SAPS Self-Management Programme: with special reference to its human relations and health maintenance components. In: WILLIAMS, H.M. The effect of the human relations and health maintenance components of the SAPS Self-Management Programme. Potchefstroom: North-West University. (PhD Thesis)

WILLIAMS, H.M. \& WEYERS, M.L. 2006. An evaluation of the human relations modules of the South African Police Service's Self-Management Programme. In: WILLIAMS, H.M. The effect of the human relations and health maintenance components of the SAPS SelfManagement Programme. Potchefstroom: North-West University. (PhD Thesis)

Dr Marili Williams, Police Social Work Services, SAPS, Pretoria; Prof Mike Weyers, Social Work Division, School for Psychosocial Behavioural Sciences, North-West University, Potchefstroom, South Africa. 